\title{
Erratum to: Synthesis and biological studies of a novel series of 4-(4-(1H-imidazol-1-yl)phenyl)-6-arylpyrimidin-2-amines
}

\author{
Mujahid Hussain Bukhari • Matloob Ahmad • \\ Tanvir Hussain • Syed Umar Farooq Rizvi • \\ Naveed Ahmad
}

Published online: 5 March 2013

(C) Springer Science+Business Media New York 2013

\section{Erratum to: Med Chem Res}

DOI 10.1007/s00044-013-0523-6

In the original version of this paper, we regret that unfortunately the name of a co-author of this paper was wrongly published. The correct name of the author is as follows "Syed Umar Farooq Rizvi".

The online version of the original article can be found under doi:10.1007/s00044-013-0523-6.

M. H. Bukhari $(\bowtie) \cdot$ T. Hussain · S. U. Farooq Rizvi .

N. Ahmad

Institute of Chemistry, University of the Punjab,

Lahore 54590, Pakistan

e-mail: mujahid_bk@yahoo.com

M. Ahmad

Department of Chemistry, Government College University,

Faisalabad 38000, Pakistan 